Supplement of Atmos. Chem. Phys., 21, 4541-4560, 2021

https://doi.org/10.5194/acp-21-4541-2021-supplement

(C) Author(s) 2021. CC BY 4.0 License.

(c) (i)

Supplement of

\title{
Investigation of several proxies to estimate sulfuric acid concentration under volcanic plume conditions
}

\section{Clémence Rose et al.}

Correspondence to: Clémence Rose (c.rose@opgc.univ-bpclermont.fr)

The copyright of individual parts of the supplement might differ from the article licence. 


\section{Temperature-dependant reaction rate constant between $\mathrm{SO}_{2}$ and $\mathrm{OH}$}

The temperature-dependant reaction rate $\mathrm{k}\left(\mathrm{cm}^{3}\right.$ molecule $\left.{ }^{-1} \mathrm{~s}^{-1}\right)$ between $\mathrm{SO}_{2}$ and $\mathrm{OH}$ is given by DeMore et al. (1997) and Sander et al. (2002):

$\mathrm{k}=\frac{\mathrm{A} \times \mathrm{k}_{3}}{\left(\mathrm{~A}+\mathrm{k}_{3}\right)} \times \exp \left\{\mathrm{k}_{5} \times\left[1+\log _{10}\left(\frac{\mathrm{A}}{\mathrm{k}_{3}}\right)^{2}\right]^{-1}\right\}$

5 where $\mathrm{A}=\mathrm{k}_{1} \times[\mathrm{M}] \times\left(\frac{300}{\mathrm{~T}}\right)^{\mathrm{k}_{2}},[\mathrm{M}]=0.101 \times\left(1.381 \times 10^{-23} \times \mathrm{T}\right)^{-1}$ is the density of air $\left(\right.$ molecule $\left.\mathrm{cm}^{-3}\right), \mathrm{k}_{1}=4 \times 10^{-31}, \mathrm{k}_{2}$ $=3.3, \mathrm{k}_{3}=2 \times 10^{-12}$ and $\mathrm{k}_{5}=-0.8$.

\section{Correlations between $\left[\mathrm{H}_{2} \mathrm{SO}_{4}\right]$ and key atmospheric variables}

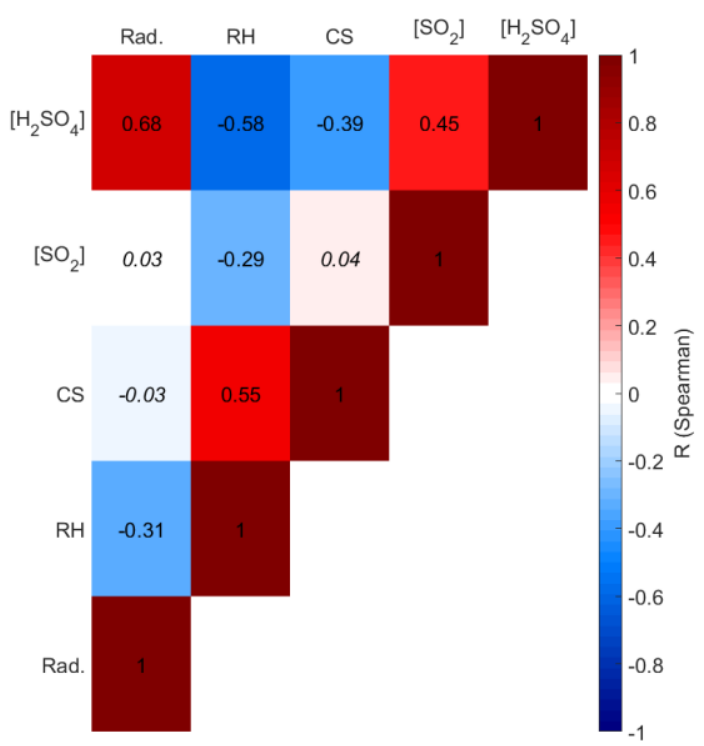

Fig. S1 Correlation coefficients (Spearman) between $\left[\mathrm{H}_{2} \mathrm{SO}_{4}\right]$ and the key atmospheric variables likely affecting $\mathrm{H}_{2} \mathrm{SO}_{4}$

10 formation in the eruptive volcanic plume of the Piton de la Fournaise during OCTAVE. The correlation coefficients are indicated by the colour code for a quick overview, and corresponding values are in addition reported on the figure for each couple of variables. Values highlighted in italic indicate non-statistically significant correlations (i.e. corresponding p-value was > 0.05). 


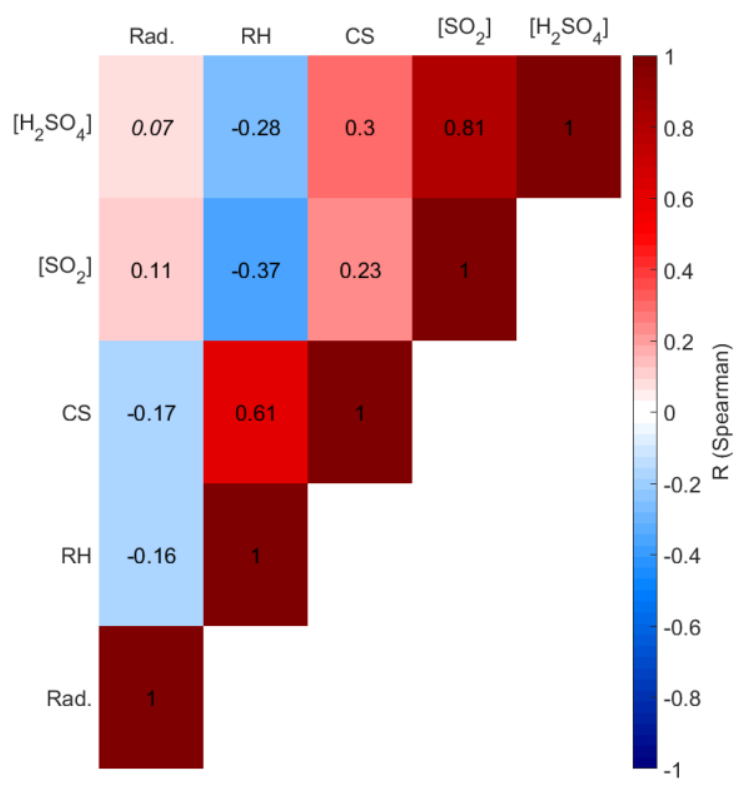

Fig. S2 Correlation coefficients (Spearman) between $\left[\mathrm{H}_{2} \mathrm{SO}_{4}\right]$ and the key atmospheric variables likely affecting $\mathrm{H}_{2} \mathrm{SO}_{4}$ formation in the passive degassing plume of Etna during the first part of flight ETNA 13 in STRAP. See Fig. S1 for an explanation of the symbols.

3. Derivation of the proxies using measurements performed in the volcanic eruption plume of the Piton de la Fournaise during OCTAVE - Effect of including $\left[\mathrm{O}_{3}\right]$ in the proxies

Table S1 Fit results after replacing global radiation by the product $\mathrm{Rad} \times\left[\mathrm{O}_{3}\right]$ in all the proxies. Note that the procedure was only applied to the original dataset (no bootstrap resampling). For simplicity, the results are reported separately for the three proxy families: a) F1-F3, which are the proxies with powers fixed to -1 or 1 for all variables, b) A1-A4, which have individual

10 adjusted powers for each variable and c) $\mathrm{S} 1$, which includes the additional $\mathrm{H}_{2} \mathrm{SO}_{4}$ sink related to cluster formation. Note that based on corresponding $p$-values, all correlations were found significant $(\mathrm{p}<0.05)$.

a)

\begin{tabular}{|c|c|c|c|c|c|}
\hline 4 & Proxy & $\mathrm{K}$ & $\mathrm{R}$ & $\mathrm{RE}$ & SSR $\left(\times 10^{19}\left(\text { molec. } \mathrm{cm}^{-3}\right)^{2}\right)$ \\
\hline F1 & & $1.49 \times 10^{-9}$ & 0.68 & 0.52 & 1.35 \\
\hline $\mathrm{F} 2$ & & $2.81 \times 10^{-7}$ & 0.54 & 0.64 & 1.99 \\
\hline F3 & & $3.51 \times 10^{-8}$ & 0.43 & 0.75 & 2.45 \\
\hline
\end{tabular}


b)

\begin{tabular}{lccccccccc}
\hline Proxy & $\mathrm{a}$ & $\mathrm{b}$ & $\mathrm{c}$ & $\mathrm{d}$ & $\mathrm{e}$ & $\mathrm{f}$ & $\mathrm{R}$ & $\mathrm{RE}$ & $\begin{array}{c}\text { SSR } \\
\left(\times 10^{19}\left(\mathrm{molec} . \mathrm{cm}^{-3}\right)^{2}\right)\end{array}$ \\
\hline A1 & $1.44 \times 10^{-10}$ & 0.77 & 0.47 & -0.47 & - & - & 0.78 & 0.45 & 0.82 \\
$\mathrm{~A} 2$ & $3.19 \times 10^{-6}$ & 0.61 & 0.39 & - & - & & 0.70 & 0.56 & 1.07 \\
A3 & $1.13 \times 10^{-7}$ & 0.68 & 0.42 & - & -0.22 & & 0.75 & 0.49 & 0.92 \\
A4 & $1.36 \times 10^{-11}$ & 0.80 & 0.49 & -0.53 & - & 0.15 & 0.79 & 0.44 & 0.80 \\
\hline
\end{tabular}

c)

\begin{tabular}{lccccc}
\hline Proxy & $\alpha$ & $\beta$ & R & RE & SSR $\left(\times 10^{19}\left(\text { molec. } \mathrm{cm}^{-3}\right)^{2}\right)$ \\
\hline S1 & $4.91 \times 10^{-9}$ & $2.78 \times 10^{-11}$ & 0.74 & 0.46 & 0.97 \\
\hline
\end{tabular}

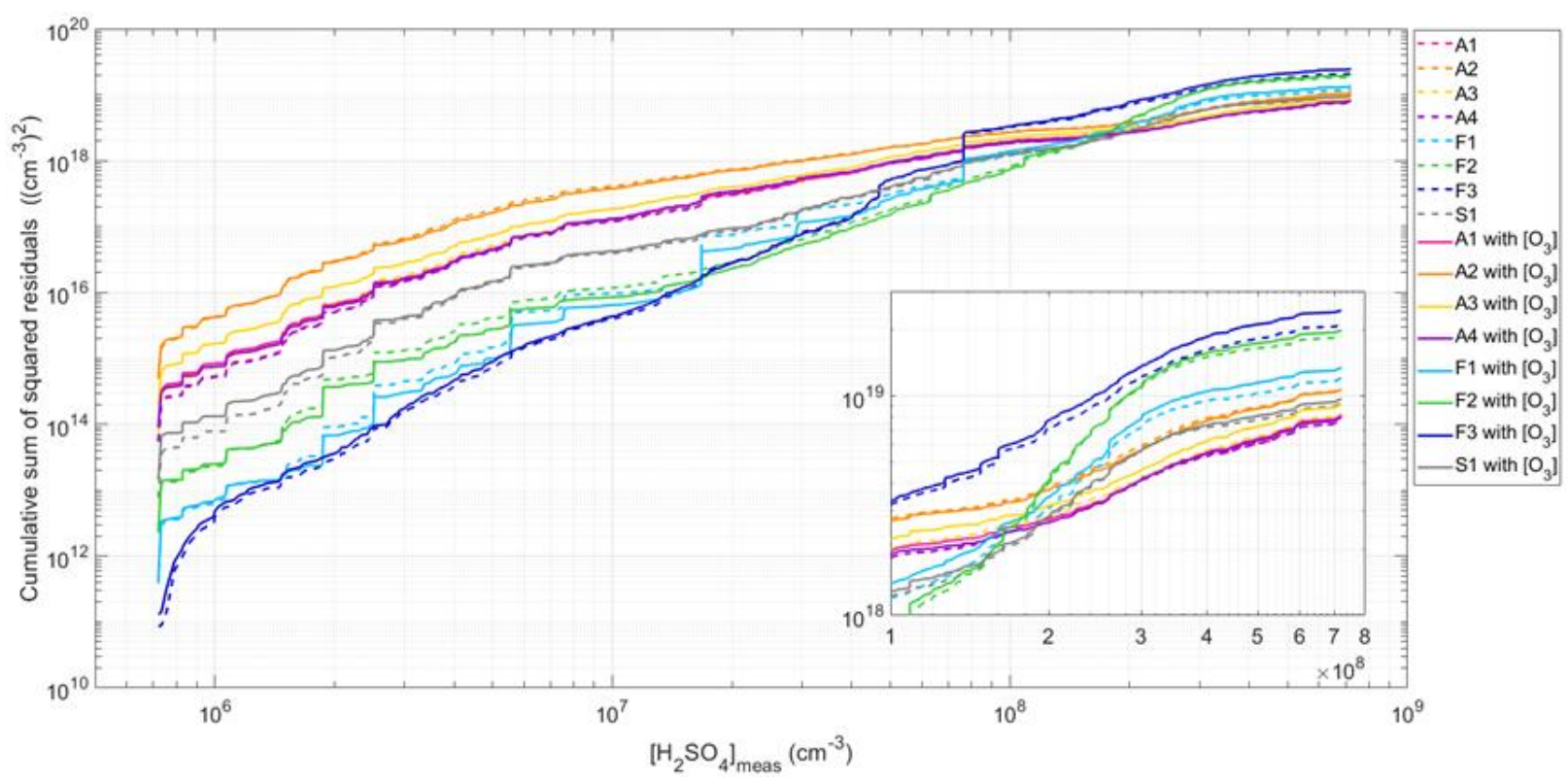

Fig. S3 Cumulative sum of squared residuals as sociated to the different proxies, with (solid lines) and without (dashed lines) the inclusion of $\left[\mathrm{O}_{3}\right]$ in the corresponding functions. The insert presents a zoom into the results obtained for $[\mathrm{H} 2 \mathrm{SO}]>1 \times 10^{8}$ $\mathrm{cm}^{-3}$. 

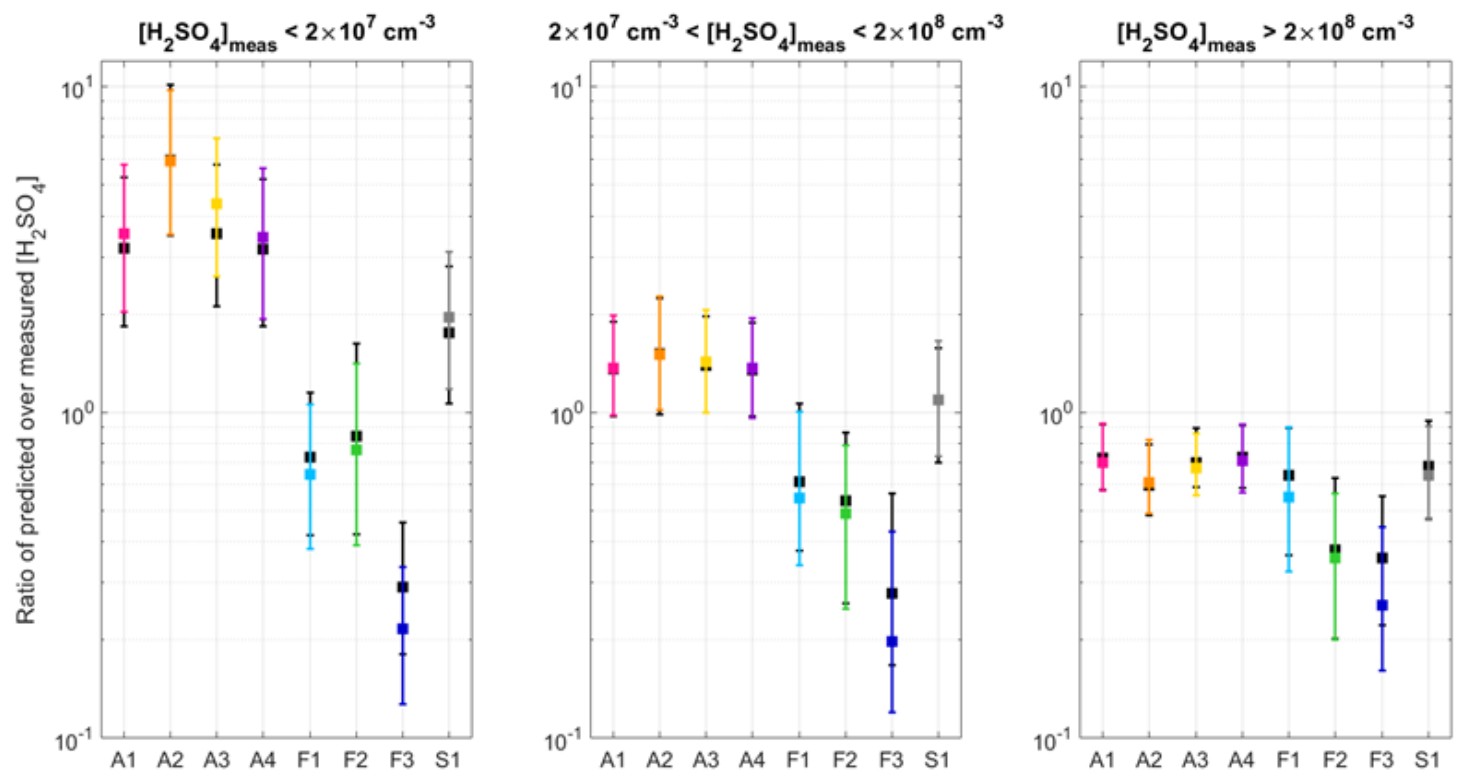

Fig. S4 Ratio between predicted and measured $\left[\mathrm{H}_{2} \mathrm{SO}_{4}\right]$ in the different $\left[\mathrm{H}_{2} \mathrm{SO}_{4}\right]$ subranges. For each proxy, the coloured marker represents the median of the ratio obtained when accounting for $\left[\mathrm{O}_{3}\right]$ in the prediction, and lower and upper limit of the corresponding error bar indicate the 25th and 75th percentiles, respectively. Black markers and error bars correspond to 5 the results shown in Fig. 5 , i.e. in absence of $\left[\mathrm{O}_{3}\right]$ in the proxies. 